\title{
Mentoring in International Assignments: \\ A Personality Traits Perspective
}

\section{Research Paper}

\begin{abstract}
:
Purpose: This study analyzes the impact of home and host country mentorship on expatriates' psychological wellbeing and identifies for whom which type of mentoring is most beneficial. We argue that expatriates with certain personality traits (Extraversion, Agreeableness, Conscientiousness, Emotional Stability, and Openness) derive more advantages from mentoring than others do.

Design/methodology/approach: Based on socioanalytic theory, we develop hypotheses and test them against data of 334 expatriates by employing a linear hierarchical regression approach.

Findings: The study reveals that home country mentorship has a significant positive impact on psychological wellbeing, whereas host country mentorship shows no significant positive effects. Moreover, the study indicates that home and host country mentorship partially moderates the relationship between personality traits and psychological wellbeing.

Originality/value: Since we derive important implications for the selection process of expatriates, as well as the implementation of mentoring in MNCs, this study is of value for researchers and practitioners in the areas of human resource management and organizational studies.
\end{abstract}

Keywords: Expatriates; International Assignments; Mentoring; Psychological Well-Being; Personality Traits 


\section{MENTORING IN INTERNATIONAL ASSIGNMENTS: A PERSONALITY TRAITS PERSPECTIVE}

\section{INTRODUCTION}

The cost of expatriation ranges from US\$300,000 to US\$1,000,000 and is typically the highest sum invested into an average employee (Downes et al., 2010; Selmer, 2001). Yet, a certain percentage of international assignments fail in the sense that expatriates are prematurely ordered back to their home organization, perform poorly, voluntarily terminate the assignment before completion, or even leave the company (Harzing, 1995; Harzing and Christensen, 2004; Reiche et al., 2011). In addition to high direct costs (Hemmasi et al., 2010; Yeaton and Hall, 2008), Multinational Corporations (MNCs) often suffer from damaged relations with clients, local businesses, and government officials, while the expatriates return home with decreased self-esteem, self-confidence, and prestige (Gupta et al., 2012; Mendenhall and Oddou, 1985). MNCs, however, strongly rely on expatriates' abilities to successfully deal with the complexities arising due to firms' increasing international activities (Harzing, 2001; Minbaeva and Michailova, 2004).

Regarding the high investment and the collateral risks, one might expect that a company will do everything in its power to make the investment a success. Psychological well-being has been considered one important aspect for HRM, not only in the local context (Grant et al., 2013; Pawar, 2016), but also in the international context, because it positively influences expatriates' intention to stay (Black and Stephens, 1989; Cao et al., 2014; Mendenhall and Oddou, 1985), decreases the chance of premature return (Black and Stephens, 1989; Caligiuri, 1997; Firth et al., 2014; Shaffer et al., 2006), and increases task performance (Devonish, 2013; Firth et al., 2014; Kraimer et al., 2001; Shay and Baack, 2006; Wright and Cropanzano, 2000). By enhancing psychological well-being, companies can render international assignments successful and secure their investment. In order to do so, it is important to select the right candidate (McNulty and De Cieri, 2016; Toh and DeNisi, 2005) and to support him/her appropriately (Kraimer et al., 2001). On the one hand, for expatriate selection it has to be considered that personality factors are even more (or at least equally) important than task-related skills, knowledge, and abilities, since they enable expatriates to cope with stress and make sense of their environment (Caligiuri, 2000a; Huff, 2013; Huff et al., 2014; O’Sullivan, 1999; Tung, 1987). Recent research provides evidence for the positive effects of expatriate personality traits on desired outcomes, e.g. cultural 
adjustment (Caligiuri, 2000b), career satisfaction (Lounsbury et al., 2003), and task performance (Motowildo et al., 1997). Nevertheless, more than 90 percent of MNCs still base expatriate selection primarily on work-related criteria, e.g., technical expertise, know-how, and abilities (Peltokorpi and Froese, 2012; Swaak, 1995). On the other hand, with regard to expatriate support during international assignments, an increasing number of scholars and practitioners advocate the instrument of not only mentoring in general (Pate and Scullion, 2010), but also home and host country mentoring (Holtbrügge and Ambrosius, 2015). Mentoring is defined as a one-to-one relationship between a mentor with advanced experience and knowledge and a mentee with less experience and knowledge with the aim of tacit know-how transfer (Bright, 2005; Mullen, 1994). Although scholars suggest that mentorship provides various benefits for expatriates during their international assignments (Carraher et al., 2008; Mezias and Scandura, 2005), little empirical research on its value and efficiency has been conducted so far. Considering MNCs' limited amount of resources and the high costs of international assignments, it becomes extremely relevant to know precisely whether a mentor is required and, if yes, to whom he/she should be allocated in order to achieve the highest degree of expatriate psychological well-being. Previous studies focused on various antecedents of expatriates' well-being and examined the influence of spouse adjustment (Black and Stephens, 1989; Lazarova et al., 2010; Simeon and Fujiu, 2000), non-work and work adjustment of expatriates (Nicholson and Imaizumi, 1993), family adjustment (Caligiuri, 2000a), family conflicts (Bader et al., 2015), social networks (Bader and Schuster, 2015; Wang and Kanungo, 2004), job performance (Kraimer et al., 2001), or work experience (Aryee and Stone, 1996). None of them, however, explicitly focus on the effects of personality traits on expatriates' psychological well-being. Furthermore, while the existing literature outlines the manifold benefits of mentorship for expatriates during their international assignments (Carraher et al., 2008; Mezias and Scandura, 2005; Zhuang et al., 2013), none of the studies systematically connects mentoring with existing theories on expatriate psychological well-being and individual personality traits.

Based on the considerations above, we aim at bridging this research gap and answer the following three interconnected research questions: (1) How are personality traits of expatriates related to psychological well-being, (2) what effects does home and host country mentorship have on psychological well-being, and (3) who benefits most from being mentored by which type of mentor? Applying socioanalytic theory, which has recently been included in research on international assignments (Peltokorpi and Froese, 2012; Shaffer et al., 2006), we developed a set of theory-driven hypotheses intended to test our objectives. 


\section{THEORETICAL FRAMEWORK AND HYPOTHESES}

\subsection{Theoretical Framework}

Recent research in expatriate management applies socioanalytic theory (Hogan et al., 1985; Hogan and Shelton, 1998) to explain the effects of personality traits during international assignments on outcome variables like cross cultural adjustment (Shaffer et al., 2006) and job performance (Froese et al., 2012; Lee et al., 2013; Peltokorpi and Froese, 2012; Shaffer et al., 2006; Wang et al., 2013). These studies assume that expatriates' individual differences facilitate their international assignment (Shaffer et al., 2006). With regard to socioanalytic theory, Hogan and Blickle (2013) state that personality traits directly influence individuals' well-being and that well-being is defined by a person's personality and the situation. Situations create social expectations and individuals will react to these expectations according to their personality (Shaffer et al, 2006). The socioanalytic theory argues that such reactions are motivated by three basic human needs which individuals strive for: (1) the need to be accepted and liked (getting along), (2) the need for status and power (getting ahead), and (3) the need for predictability and order (finding meaning) (Peltokorpi and Froese, 2012; Shaffer et al., 2006). Socioanalytic theory is based on the assumption that there are individual differences in the ability to satisfy these needs descending from the individuals' personality traits (Hogan and Shelton, 1998). According to Hogan and Roberts (2000), ambiguous situations are especially stressful because of uncertainties about social roles and how to comply with them. During international assignments, expatriates are frequently exposed to these ambiguous situations in which norms for behavior are unclear and individuals interacting in these situations do not share a common understanding of what is expected of them (Shaffer et al., 2006). Consequently, behaviors and their outcomes tend to be determined by expatriates' characteristics. Since expatriates live and work in environments that are less clear with regard to social expectations than domestic domains, personality may be more strongly linked with psychological well-being.

Applying the theory to personality traits within the context of expatriation leads to the assumption that if MNCs treat their expatriates according to their individual differences, they can help them satisfy their needs and thus increase their psychological well-being. Mentoring is an instrument which is often used within this context as it can be tailored to the needs of the individual (Ambrosius, 2016; Young and Perrewe, 2000). Mentors are points of contact who emotionally and professionally support expatriates before, during, and after an assignment (Mezias and Scandura, 2005). Within the context of international assignments, mentoring provides a wide array of advantages for the organization 
and the individuals involved. The advantages are, among others, decrease of turnover intentions (Stroh, 2016), increased organizational knowledge (Crocitto et al., 2005), skill and career development (Holtbrügge and Ambrosius, 2015), expatriate effectiveness (Carraher et al., 2008) and expatriate socialization (Feldman and Bolino, 1999). In literature, it has often been advocated that the outcomes of mentoring, amongst others, depend on the personality of the mentee (Haggard et al., 2011). Turban and Lee (2007) have further emphasized the effects of personality traits in mentoring relationships. They argue that different personality traits of the mentee might lead to different outcomes in distinct phases of the assignment.

In line with socioanalytic theory, in the following we thus argue that personality traits and mentoring not only have a direct effect on expatriates' psychological well-being, but that individuals with certain personality traits can benefit to a greater extent from the supportive behavior of home country and host country mentors.

\subsection{Hypotheses}

By applying socioanalytic theory to expatriation, we argue that expatriates' personality traits determine their ability to react to expectations in ambiguous and complex situations and thus to satisfy their basic human needs (get along, get ahead, and find meaning) (Hogan and Shelton, 1998). The degree to which these needs are satisfied then in turn defines expatriates' psychological well-being. Within this context, previous research focused on the "Big Five" or five-factor model (Huang et al., 2005; Shaffer et al., 2006) which contends that most personalities can be classified according to five distinct general traits, namely extraversion, agreeableness, conscientiousness, emotional stability, and openness. Based on socioanalytic theory, in the following we describe how the different personality traits enable expatriates to get along, get ahead, and to find meaning during their assignment.

\section{Extraversion.}

During an assignment, expatriates have to abandon their familiar social network in the home country, which is often accompanied by the loss or at least limitation of social support (Bader and Schuster, 2015). Expatriates who are able to deal with these circumstances will have a reduced psychological well-being. Extraverted expatriates have the ability to better face this challenge as they are enthusiastic, communicative, and talkative (Gosling et al., 2003). According

to the studies by O'Sullivan (1999), extraversion refers to an interpersonal orientation, or a willingness to develop interpersonal relationships with people in general. Due to these characteristics, when interacting with people from the 
host country, extraverted expatriates can easily establish new networks or broaden their existing one. Based on socioanalytic theory it can be stated that they thus keep receiving social support, which satisfies their need to get along and leads to a higher psychological well-being (Chiu et al., 2009; Johnson et al., 2003; Shaffer et al., 2006).

\section{Agreeableness.}

During an international assignment, expatriates are often considered as outgroup members by locals and colleagues, e.g. due to pay and status differences, personal values, or ethnocentric attitudes and are therefore treated differently (Alserhan et al., 2009; Al-Waqfi and Forstenlechner, 2010; Florkowski and Fogel, 1999) which has tremendous negative effects on expatriates' psychological well-being. Under certain circumstances, outgroup categorization does not necessarily lead to outgroup discriminatory behavior (Guimond et al., 2002). Agreeable expatriates are characterized as pleasant, complimentary, sympathetic, and warm (Gosling et al., 2003). They seek to agree with local norms, values, and behavior, which helps them to be accepted and liked by host country nationals (HCN) (Caligiuri, 2000a; Ones and Viswesvaran, 1999). Furthermore, agreeable expatriates tend to be altruistic and to help HCN colleagues in completing tasks (Ones and Viswesvaran, 1997). With regard to socioanalytic theory, for expatriates, this increases the feeling of being part of the group and satisfies the need to get along, which ultimately leads to psychological well-being (Shaffer et al., 2006).

\section{Conscientiousness.}

During an international assignment, when working together with individuals from another culture, different behaviors for achieving goals may emerge and finding common ground might be complex (Peltokorpi, 2010). Not being able to face this challenge can have enormous negative effects on the expatriates' psychological well-being. Conscientious individuals are able to face this challenge, as they are willing to take over responsibility, are determined, attentive, committed to their tasks and tend to conduct them in an orderly and well-planned manner (Caligiuri, 2000a; Ones and Viswesvaran, 1999). Their willingness to take responsibility and their task-oriented behavior makes them an appreciated part within the team, which helps them to get along. Their determinedness enables them to achieve their goals, even when they face obstacles arising due to different cultural backgrounds (Shaffer et al., 2006). Additionally, due to their personality traits they are more likely to be promoted and get more challenging tasks (Caligiuri, 2000a) and are thus more respected within their team and organization. This satisfies their need to get ahead. Their attentiveness facilitates their understanding of the host culture due to the observations they make, which enables them to create a 
holistic picture of the host culture and satisfies their need to find meaning. From a socioanalytic perspective, conscientious expatriates' ability to find meaning, to get along and to get ahead increases his/her psychological well-being (Shaffer et al., 2006).

\section{Emotional stability.}

As argued above, having to abandon the familiar social network in the home country is often accompanied with the loss or at least limitation of social support (Bader and Schuster, 2015). Expatriates who have difficulties building a new social network may suffer from decreased psychological well-being. Emotionally stable expatriates may be better able to face this challenge, as a study by Huang et al. (2005) indicates, as they are good at interacting with the local organizational members or with other HCNs. It is therefore easier for them to establish a new social network, which gives them comfort and increases their psychological well-being. It is argued that emotionally stable expatriates can better cope with cultural differences as they tend to stay calm and relaxed in stressful situations during their assignment. Therefore, emotional stability might reduce the well-known psychological discomfort often associated with international relocations (Shaffer et al., 2006) and enables them to feel comfortable when meeting new people. This will help them to better get along with HCNs. Their confident attitude will increase their visibility within the host organization and ultimately help them to get ahead. Since emotionally stable individuals are characterized by a high degree of self-acceptance, it is easier for them to take an objective viewpoint on their host culture. This enables them

to create a more realistic picture of the culture and helps them to find meaning in the culture. Based on socioanalytic theory, it can thus be stated that the ability of emotionally stable expatriates to find meaning and to get along increases their psychological well-being (Shaffer et al., 2006).

\section{Openness.}

When being exposed to an unfamiliar environment, expatriates experience uncertainty due to ambiguous or uninterpretable social cues (Caligiuri, 2000a). This means that they may not be able to interpret HCNs' behavior, because they have been socialized differently. Expatriates who lack the ability to face this challenge, may face a critical decrease in psychological well-being. Individuals characterized by a high degree of openness are able to face this challenge, as they are curious and have less rigid views and thus enter a host country with fewer stereotypes and false expectations (Huang et al., 2005). They hence tend to understand and accept the new culture more easily (Huang et al., 2005). Individuals who are open possess the ability to correctly assess their social environments and to correct mistaken attributions (Abe and Wiseman, 1983; Caligiuri, 2000a; Shaffer et al., 2006). This ability to predict, interpret, 
and align HCNs' behavior reduces uncertainty and facilitates adjustment and performance (Mendenhall and Oddou, 1985; Shaffer et al., 2006), which will facilitate the expatriates' endeavor to find meaning within the culture.

At large, our derivations above explain the positive effects of distinct personality traits during international assignments on psychological well-being. In line with socioanalytic theory, we explained how different personality traits can help expatriates to react in complex and ambiguous situations occurring during international assignments. Therefore, we hypothesize:

Hypothesis 1a-1e: (a) Extraverted, (b) agreeable, (c) conscientious, (d) emotionally stable, and (e) open-minded expatriates will have a higher psychological well-being during international assignments than expatriates with opposite personality traits.

While the relationship between personality traits and antecedents to psychological well-being is quite well established in the existing literature, the connection between mentoring and psychological well-being is entirely underdeveloped. Studies like, for example by Carraher et al. (2008), take the effects of home and host country mentoring on several outcomes into account, such as effectiveness. However, so far psychological well-being is neglected in studies on mentoring for expatriates.

Similar to the study by Carraher et al. (2008), we assume that both host and home country mentoring has positive effects on expatriate outcomes, in our case on psychological well-being. With recourse to socioanalytic theory, we argue that both home country and host country mentorship can help expatriates to satisfy the three basic needs, which leads to an increased psychological well-being. Our assumptions will be explained in more detail in the following. According to Crocitto et al. (2005), mentoring international expatriates requires that mentors have knowledge of the expatriate's country of origin, the host country, the organization, as well as the expatriation process. In fact, especially former expatriates who have successfully completed an assignment in the same location often act as home country mentors and support potential and new assignees (Downes et al., 2002). Furthermore, the home country mentor was socialized in the same culture, which decreases the danger of intercultural misunderstandings and miscommunication in the mentoring relationship. From a socioanalytic theory perspective, we can assume that home country mentoring enables expatriates to better get along, get ahead, and to find meaning. First, home country mentors can facilitate expatriates' efforts to get along by helping them to quickly establish a new social network in the assigned countries. This is due to the fact that they may be in close contact with their colleagues in the foreign subsidiaries or with fellow expatriates who are on their international assignment and can introduce them to the expatriates. Second, home country 
mentors can support expatriates with work-related tasks and thus with getting ahead by providing them with relevant and accurate information about their job and the related tasks, which helps reducing wrong expectations and leads to a realistic job preview (Carraher et al., 2008; Wanous et al., 1992). Finally, home country mentors can help expatriates to find meaning by helping them to correctly interpret unfamiliar norms, values, and behavior, since they have often experienced the cultural differences first hand.

Besides home country mentorship, mentoring from the host country is also crucial for the psychological well-being of expatriates. The host country mentor may provide valuable assistance during the on-site stage of the assignment by guiding expatriates through the challenges of the local organization and community environment and providing intercultural training (Carraher et al., 2008; Holtbrügge and Ambrosius, 2015). Drawing on socioanalytic theory, we argue that a host country mentor helps expatriates in their efforts to get along, get ahead, and find meaning. He/she can support expatriates in assimilating into the organization's culture and feel more comfortable with the work group (Heimann and Pittenger, 1996; Morrison, 1993), which in turn can increase expatriates' ability to get along with colleagues. Additionally, he/she may provide newcomers with useful advice about avoiding political pitfalls in managing their careers (Chao et al., 1992), which leads to career progress (getting ahead) in the host unit. Furthermore, by explaining expatriates the cultural values which are underlying the behavior of the host country nationals, the host country mentor may help to find meaning within the host culture.

Cultural differences between the host country mentor and the mentee, however, could diminish the positive effects of host country mentoring (Mezias and Scandura, 2005). Even though host country mentors can facilitate establishing new networks (getting along), avoiding political pitfalls (getting ahead), or assimilating with host country organization culture (finding meaning), mentoring across geographic and cultural boundaries leads to additional challenges as compared to a domestic setting (Fee et al., 2011). In general, cross-cultural relationships between expatriates and host country nationals are difficult to maintain due to cultural differences which may lead to conflicts (Feldman and Thomas, 1992; Toh and DeNisi, 2005). The same can be assumed for the relationship between expatriates and their host country mentor, as studies posit that the amount of mentoring received is comparably low in cross-cultural mentoring relationships (Feldman et al., 1999). Even though we expect that host country mentoring may be not as beneficial as home country mentoring, we still assume a positive relationship. Based on socioanalytic theory, we thus conclude: 
Hypothesis 2a): Having a host country mentor will be positively related to psychological well-being during international assignments

Hypothesis 2b): Having a home country mentor will be positively related to psychological well-being during international assignments

Besides these direct effects, mentoring might also have several moderating effects on the relationship between personality traits and psychological well-being. In particular, in the following we will show that being mentored will be more beneficial for expatriates with certain personality traits.

\section{Interaction with extraversion.}

A host country mentor facilitates the extension of the social network of extraverted expatriates in the host organization, as host country mentors can introduce expatriates to locals (Crocitto et al., 2005). Since extraverted expatriates are characterized as talkative and like to approach new people, they will be able to fully benefit from the introduction to new people by a mentor. Mentoring thus reinforces the positive effects of extraverted expatriates' characteristic of being talkative and further allows them to extend their social network. As a result, due to a combination of their ability to talk to people and the introduction to networks by the mentor, expatriates can obtain a higher amount of social support (Bader and Schuster, 2015). With regard to socioanalytic theory, we state that a host country mentor further helps extraverted expatriates to get along with locals and thus strengthens the relationship between extraversion and psychological well-being. We hence come to the following conclusion:

Hypothesis 3a): Having a host country mentor will strengthen the relationship between extraversion and psychological well-being.

Furthermore, we argue that having a home country mentor during the assignment also has a positive influence on the relationship between extraversion and expatriates' psychological well-being. Literature has shown that home country mentors have, in most cases, also successfully completed an international assignment. Since they thus possess knowledge about the host country and knows locals, based on socioanalytic theory, we state that the host country mentor can also support extraverted expatriates in getting along. We hence assume that the home country mentor can lead to a reinforcement of the relationship between extraversion and psychological well-being:

Hypothesis 3b): Having a home country mentor will strengthen the relationship between extraversion and psychological well-being. 


\section{Interaction with agreeableness.}

Host country mentors help their mentees to be a part of the local group at work or in their leisure, since they provide expatriates with advice on how to deal with cultural problems (Feldman and Bolino, 1999; Mezias and Scandura, 2005). Since agreeable expatriates are characterized as being perceptive, they will be able to embrace the advice by the mentor and benefit from it. This will help them to understand how locals think and enable them to adapt their behavior to local norms and values. Host country mentoring thus reinforces the positive effects of agreeable expatriates' characteristic of being perceptive and enables them to fit into the group. In line with socioanalytic theory, we argue that having a host country mentor further enables agreeable expatriates to get along with locals and thus strengthens the relationship between agreeableness and psychological well-being.

Hypothesis 4a): Having a host country mentor will strengthen the relationship between agreeableness and psychological well-being.

According to Carraher et al. (2008), home country mentors strengthen expatriates' belief in the home country organization. This statement implies that home country mentors may reinforce the home country/unit's perspective about what is right or wrong and what will work or not because of the mentor's latently present home country perspective. Since agreeable expatriates want to accommodate the local norms and adapt to the local behavior, this constant reinforcement of the home country culture by the mentor may lead to an inner conflict of agreeable expatriates. This inner conflict makes it more difficult for them to get along with the locals, because they may not know according to which culture to act. With regard to socioanalytic theory, we thus follow that having a home country mentor has negative effects for agreeable expatriates: and conclude the following:

Hypothesis 4b): Having a home country mentor will have a negative impact on the relationship between agreeableness and psychological well-being.

\section{Interaction with conscientiousness.}

Host country mentors facilitate the process of being part of cross-cultural teamwork for conscientious expatriates and thus increase psychological well-being due to several reasons. Conscientious expatriates are more likely to spend more time on tasks and to meet job expectations even when facing obstacles (Ones and Viswesvaran, 1997; Shaffer et al., 2006), leading to a good reputation within the organization. Since the host country mentor can provide expatriates with information about the host organization, conscientious expatriates are even more able to face challenges. 
Combined with the strong will and task orientation of conscientious expatriates, a host country mentor thus enables conscientious expatriates to get ahead.

Host country mentors can support expatriates by giving information about the procedure of the assignment and how to prepare for the interaction with locals (Feldman and Thomas, 1992; Mezias and Scandura, 2005). Like this, having a host country mentor will further strengthen the reputation and trustworthiness of expatriates among the locals (McClelland, 2009). Having a host country mentor will thus enable conscientious expatriates to enhance the socialization within the organization and support expatriates in getting along with locals (Florkowski and Fogel, 1999).

Furthermore, host country mentors can support expatriates in becoming familiar with local values, norms, and beliefs. Since conscientious expatriates are attentive (Kim and Slocum, 2008), this knowledge could even further enhance their ability to understand the local culture. In combination with the attentiveness of conscientious expatriates', the mentor thus supports conscientious expatriates in finding meaning. Based on socioanalytic theory we thus argue that a host country mentor strengthens the relationship between being conscientious and psychological well-being. Hence, we hypothesize:

Hypothesis 5a): Having a host country mentor will strengthen the relationship between conscientiousness and psychological well-being.

Based on our explanations above, we state that a home country mentor can support conscientious expatriates mostly with getting ahead. First of all, a mentor from the home organization will further increase the good reputation of conscientious expatriates within the host organization (Florkowski and Fogel, 1999). Second, due to the fact the home country mentors have often been expatriates themselves, they can also inform expatriates about important aspects of assignments in general. This will increase the conscientious ability to deliver tasks reliably even in the face of challenges, which will lead to conscientious expatriates to get ahead. With regard to socioanalytic theory we hypothesize:

Hypothesis 5b): Having a home country mentor will strengthen the relationship between conscientiousness and psychological well-being.

\section{Interaction with emotional stability.}

By providing psychosocial support, host and home country mentors may reduce expatriates' (expectedly high) stress level during the assignment (Carraher et al., 2008; Florkowski and Fogel, 1999; Mezias and Scandura, 2005). 
This reduced stress level increases the calmness and self-composure of emotionally stable expatriates and hence supports them in getting along with others well on the assignment.

Moreover, having a home or host country mentor may enhance expatriates' organizational identification because they recognize the time and effort invested by the organization in making the assignment a success (Black and Mendenhall, 1990; Morris and Robie, 2001). This leads to a perception of being valued by both home and host organization and in combination with the emotionally stable expatriates' confidence may result in them taking a leading role, which in turn helps them to further get ahead.

Since emotionally stable expatriates accept their own identity, it is easier for them to get involved in the host culture.

Being mentored can further help emotionally stable expatriates to get involved, as their mentor can support them in acquiring country- and culture-specific knowledge. This helps expatriates to find meaning within the culture. Based on socioanalytic theory we thus state that home and host country mentors can support emotionally stable expatriates in satisfying all the needs postulated by the theory. We therefore argue:

Hypothesis 6a): Having a host country mentor will reinforce the relationship between emotional stability and psychological well-being.

and

Hypothesis 6b): Having a home country mentor will reinforce the relationship between emotional stability and psychological well-being.

\section{Interaction with openness.}

Expatriates with a high degree of openness are expected to be especially receptive to learning about the host culture from the host country mentor due to their curiosity. In particular, socioanalytic theory argues that curiosity enhances expatriates' intrinsic desire to understand the local environment during the international assignment. Mentoring may satisfy this desire, since host country mentors can teach expatriates about the peculiarities of the local environment (Carraher et al., 2008), which will further increase expatriates' understanding of the local environment and help to find meaning. Furthermore, open expatriates are characterized by the ability to correctly predict HCN behavior (Mendenhall and Oddou, 1985). The explanations by the host country mentor thus further reduce uncertainty and facilitate well-being. Based on socioanalytic theory we thus state that having a host country mentor reinforces the positive effects of openness on expatriates' psychological well-being. Thus, we suggest: 
Hypothesis 7a): Having a host country mentor will strengthen the relationship between openness and psychological well-being.

As home country mentors often have successfully completed an international assignment, they also have some experience as an expatriate and in the ideal case in the culture of the host organization. The home country mentor can hence also help open expatriates to make correct assumptions about HCN behaviors and to correct mistaken attributions. Based on socioanalytic theory, we thus argue that having a home country mentor also helps open expatriates to find meaning and thus increases the effects of openness on psychological well-being.

Hypothesis 7b): Having a home country mentor will strengthen the relationship between openness and psychological well-being.

Our research model is illustrated in Figure 1.

-- Insert Figure 1 about here -

\section{RESEARCH DESIGN AND METHODOLOGY}

In order to test our hypotheses, an extensive desk research was needed to identify potential respondents, since an accessible database of expatriates does not exist. This was done by collecting names and contact details based on information provided by expatriates in different professional social network platforms, such as LinkedIn. Moreover, in order to obtain a large number of respondents, we contacted companies directly and asked them to distribute the survey among their expatriates. We developed an online questionnaire in English language and created two identical versions - a personalized and a non-personalized one - before we invited potential expatriates to participate in our survey. We sent out a personalized letter of invitation which briefly described the purpose of the study and kindly asked to participate, including a token-based link to our online questionnaire. After two weeks, a reminder was sent out. In total, we personally invited 1,552 expatriates and received 160 complete datasets, which accumulates to a response rate of 10.3 percent. Moreover, the non-personalized version yielded 174 complete datasets, which accounts for a total sample of 334 cases. We followed the recommendations of Armstrong and Overton (1977) and compared the data of early and late respondents in the personalized dataset (77.5 percent who responded to the first mailing vs. the 22.5 percent who responded after the reminder) on all dependent and independent constructs. As we found no significant difference between early and late respondents $(\mathrm{p}<0.05)$, we do not expect non-response bias to be a problem and used the data without further correction. Furthermore, as we found no differences when comparing the 
means of all dependent and independent constructs between personalized $(\mathrm{N}=160)$ and anonymous datasets $(\mathrm{N}=174)$, we used the complete dataset of 334 cases without further correction.

In addition, we followed several recommendations suggested by Podsakoff et al. (2003) and Chang et al. (2010) to minimize potential common method variance (CMV). Ex-ante, we ensured the complete anonymity of all respondents and separated survey questions measuring independent and dependent constructs. Ex-post, we applied an exploratory factor analysis and examined the unrotated factor solutions in order to test for a potential common method bias in our survey approach. This was done by means of the commonly used Harman's single factor test (Harman, 1976; Podsakoff and Organ, 1986). If a substantial amount of CMV is present in a given data set, either a single factor will emerge or one general factor will account for the majority of the covariance among the variables (16.08 percent of variance in this study). However, more recent research encourages authors to address further remedies regarding CMV (Chang et al., 2010). Following these recommendations, we applied a common latent factor (CLF) test using AMOS 23. Since our results did not exceed the suggested threshold (Nurmi and Hinds, 2016), in combination with our other procedures we conclude that CMV is not a problem here.

\section{Measures}

All variables employed in this study are based on validated measures from existing literature. Our dependent variable psychological well-being was measured with an 18-item scale developed by Ryff and Keyes (1995), which has regularly been applied in previous studies dealing with international assignments (e.g. Bader and Schuster, 2015; Li and Rothstein, 2009; Wang and Nayir, 2006). Based on the multiple-item scale, we created a composite factor by averaging the 18-items, since the value for Cronbach's Alpha (.73) met the recommended threshold value (Nunally and Bernstein, 1978).

In order to measure the Big Five personality traits (extraversion, agreeableness, conscientiousness, emotional stability, and openness), we employed the Ten-Item Personality Inventory (TIPI). The TIPI is a brief self-administered inventory, which has been proven to be a valid and reliable scale (Gosling et al., 2003). Despite the fact that shorter scales are typically psychometrically inferior to multiple-item scales, shorter measures, like the TIPI, indeed have several advantages (De Boer et al., 2004; Nagy, 2002) such as minimizing fatigue, frustration, and boredom of respondents (Gosling et al., 2003; Robins, 2001; Saucier, 1994). 
The variables home country mentor and host country mentor were measured by asking the respondents whether they were assisted by a home country mentor and a host country mentor. Both variables (for home and host country mentor) were binary coded with $1=$ yes and $0=$ no-

Finally, we included a number of control variables (age, gender, time on assignment, family accompanied, international experience, compensation satisfaction, and self-initiated expatriation) which have been utilized in previous studies on international assignments (Caligiuri, 2000b; Reiche et al., 2011) and which might impact psychological well-being. Age was self-reported in years, Gender was dummy-coded $(0=$ male, $1=$ female $)$ and time on assignment indicates how long expatriates were on their current/most recent assignment and was self-reported in months. For instance, it has been argued that older expatriates have an easier time adjusting to being abroad as they can draw from a bigger (life) experience (Bader and Schuster, 2015) and thus also have a higher psychological well-being. Moreover, we included the variable family accompanied, which was binary coded $(0=$ no, $1=$ yes $)$, as expatriates with a family have an area of familial retreat, which ideally leads to increased psychological well-being. International experience, was measured on a five-point Likert scale by asking the respondents to assess the extent of previous international experience ( 1 =not at all, $5=$ extensively). Respondents also had to indicate their satisfaction with their compensation package. We adopted a two-item scale from Brewster, Suutari and Bonache (2005) and asked the respondents to indicate on a 5 -point rating scale $(1=$ not satisfied at all $-5=$ extremely satisfied $)$ as to how satisfied they were with (1) their current salary and (2) their compensation package as a whole. We created a composite factor by calculating the arithmetical average of both items $(\alpha=0.86)$. Our last control variable Self-initiated Expatriation was measured by asking the respondents whether the international assignment was "self-initiated" or "initiated by the organization" $(0=$ initiated by the organization, $1=$ self-initiated $)$. The use of this control variable stems from the fact that selfinitiated expatriation is as a growing phenomenon within the global labor market. Literature found that self-initiated expatriates differ from traditional expatriates with regard to several aspects, like, e.g., higher difficulties to adjust (Doherty et al., 2013; Selmer and Lauring, 2014).

\section{RESULTS}

Error! Reference source not found. presents the means, standard deviations, and correlation coefficients of all variables. The descriptive results show that 61.80 percent of the expatriates are male with an average age of 38.83 years and an average time on the assignment of 31.75 month. Thus, with regard to demographic characteristics, our 
sample is widely comparable to other studies in this field (Bader and Schuster, 2015; Chen et al., 2010; Wang et al., 2014). Table 1 indicates that gender, family accompanied, compensation satisfaction, self-initiated expatriation, all personality traits, as well as host country mentoring are correlated with our dependent variable psychological wellbeing. To gain further insights, we conducted a regression analysis and tested the developed hypotheses. Additionally, we included interaction terms stepwise in our multivariate regression analyses, aiming to analyze the potential moderating effect of home and host country mentoring on the relationship between personality traits and psychological well-being. This helps to reduce multicollinearity (Dawson, 2014).

To minimize further potential multicollinearity regarding predictor variables, we standardized all independent variables (dummy variables excluded) before calculating the respective interaction terms. As recommended by Aiken and West (1991) we included the respective interaction terms in separate regression models. Finally, we tested for multicollinearity by evaluating the variance inflation factors (VIF) of all variables. The VIF of all control and independent variables as well as interaction terms is 1.816 or lower and are thus substantially lower than the recommended threshold of 10 (Hair et al., 2006). Therefore, multicollinearity was not considered a problem. The results of the regression models are presented in Error! Reference source not found..

-- Insert Tables $1 \& 2$ about here--

The control model (control variables only) explains only a small share of the variance in psychological well-being $\left(R^{2}=0.053, p<0.01\right)$. The control model reveals that gender $(\beta=0.156, p<0.01)$, family accompanied $(\beta=0.098, p$ $<0.10)$ and compensation satisfaction $(\beta=0.183, \mathrm{p}<0.01)$ significantly and positively affect expatriates' psychological well-being, whereas self-initiated expatriation shows a significant negative effect on expatriates' psychological well-being $(-.109, \mathrm{p}<0.10)$. The effects of age, time on assignment, and international experience are insignificant throughout all models. In the base model, we added the five personality traits (extraversion, agreeableness, conscientiousness, emotional stability, and openness) as well as home country and host country mentorship. These variables make a significant contribution over and above the base model $\left(\mathrm{R}^{2}=0.259, \mathrm{p}<0.01\right)$. The base model shows that extraversion $(\beta=0.185, \mathrm{p}<0.01)$, conscientiousness $(\beta=0.196, \mathrm{p}<0.01)$, emotional stability $(\beta=0.226, \mathrm{p}<0.01)$ and openness $(\beta=0.134, \mathrm{p}<0.05)$ have a significant positive impact on psychological well-being, whereas agreeableness $(\beta=0.011, \mathrm{p}>0.10)$ does not show a significant direct influence on psychological well-being. As a result, Hypotheses 1a, 1c, 1d, and 1e are supported, whereas Hypothesis 1b, in which we assumed a positive relationship between agreeableness and psychological well-being, has to be rejected. Moreover, our base model indicates that 
home country mentoring $(\beta=0.100, \mathrm{p}<0.05)$ has a significant positive impact, whereas host country mentoring $(\beta=$ $0.011, \mathrm{p}>0.10$ ) shows only a non-significant positive effect on psychological well-being. Hence, Hypothesis $2 \mathrm{a}$ has to be rejected, whereas Hypothesis $2 \mathrm{~b}$ is supported by our data. As all variables show consistent values in the following models, we only discuss the moderating effects and focus on significant findings. In the following models (Model 110) we separately integrated the interaction terms. The results of the moderated regression only show a significant $\Delta \mathrm{R}^{2}$ for model 2, model 9 and model 10. Model 2 indicates that having a home country mentor significantly influences the relationship between agreeableness $(\beta=-0.088, \mathrm{p}<0.10)$ and psychological well-being, whereas model 9 and model 10 highlight a significant impact of host country mentorship on the respective relationships between emotional stability $(\beta=-0.104, \mathrm{p}<0.10)$ and openness $(\beta=0.096, \mathrm{p}<0.10)$ and psychological well-being. As a result, Hypotheses 4-7, in which we hypothesized that home country as well as host country mentorship will have a certain effect on the relationship between personality traits and psychological well-being can only be partially supported.

\section{DISCUSSION}

We investigated how the personality traits of expatriates as well as having a home and host country mentor impact their psychological well-being during international assignments. Our results confirm that extraverted, conscientious, emotionally stable, and open-minded expatriates show a higher psychological well-being than introverted, less conscientious, emotionally unstable, and close-minded expatriates.

Interestingly, agreeableness only has a non-significant positive influence on psychological well-being. In order to get a deeper understanding, it is reasonable to take a closer look at the items of psychological well-being. According to Ryff and Keyes (1995), one aspect of feeling comfortable is to have confidence in one's own opinions even if they are contrary to the general consensus. In fact, as an individual has been socialized in his/her home country, their expectations of a certain behavior differs from the host country's general consensus, as HCNs have different cultural backgrounds and different expectations (Hoersting and Jenkins, 2011). Living and working in a new culture thus goes along with being confronted with norms, values, and behaviors which contradict one's own assumptions about what is right or wrong and what will work or not work (Rajasekar and Renand, 2013). Taking into consideration that ex-

patriates who score high on agreeableness aim at solving conflicts in ways that are customary to HCNs, we assume that the insignificant findings may be caused by the fact that highly agreeable expatriates feel, to some extent, an inner conflict about living according to their own socialization. This may have adverse effects on their attempt to find 
meaning and thus reduce their psychological well-being. This effect, however, is compensated by the assumed positive relationship between agreeableness and getting along. Since agreeable expatriates have the need to get along with people, they may not understand deeper meanings. However, this is balanced by their motivation to get along which explains the insignificant effect of agreeableness on psychological well-being.

A second interesting finding is that home country mentorship turned out to be beneficial for expatriates' psychological well-being, whereas host country mentorship shows only a non-significant positive relationship. In Hypotheses 4-7, we argued that in most cases home and host country mentors will have a reinforcing effect on the relationship between personality traits and psychological well-being. According to our assumptions, however, while the findings highlight that having a home country mentor has a direct positive effect on psychological well-being, we find a significant negative interaction term between agreeableness and psychological well-being. In other words, expatriates who have a home country mentor and show a high agreeableness have a lower psychological well-being compared to expatriates with a low degree of agreeableness. Thus, having a home country mentor weakens the positive effect of agreeableness on psychological well-being. Error! Reference source not found. illustrates the moderating effect of home country mentorship on the relationship between agreeableness and psychological well-being.

-- Insert Figure 2 about here --

Considering our argument that expatriates who score high on agreeableness may experience a higher inner conflict helps us to understand the negative moderating effect of home country mentors. Carraher et al. (2008) highlight that home country mentors strengthen expatriates' beliefs in the home country organization, resulting in a higher organizational identification. This statement implies that home country mentors may reinforce the home country/unit's perspective about what is right or wrong and what will work or not because of the mentor's latently present home country perspective. For instance, when expatriates experience a conflict during their international assignment they might discuss the situation with the home country mentor who has been socialized in the same cultural environment as the expatriate him/herself. Although mentors from the home country may have a background in the host country, the results of the moderation show that even though this may have been the case, the culture of the home country is still inherent to the mentor. Since we do not know for how long the mentor has been in the host country, we cannot clearly indicate whether the mentor may have lost the knowledge over time. Therefore, it seems reasonable to argue that the home country mentor shares similar assumptions about a certain behavior and reassures expatriates about their opinion. As highly agreeable expatriates try to live up to host country expectations and behavior, this reassurance might 
cause an even higher inner conflict which consequently offsets other benefits for the expatriates' psychological wellbeing obtained from the home country mentor. This finding is also in line with socioanalytic theory, since the focus of the link between agreeableness and psychological well-being lays on interpersonal relationships. When a mentor reinforces (unknowingly) negative or wrong assumptions, the ability of agreeable expatriates to get along with people from the host country will be further distorted because of increasing communication problems and eventually even stereotyping.

A third interesting finding refers to the significant negative moderating effect of host country mentors on the relationship between emotional stability and psychological well-being. As Error! Reference source not found. highlights, emotionally stable expatriates have a higher psychological well-being if they do not have a host country mentor. -- Insert Figure 3 about here --

As argued in Hypothesis 1d, expatriates who score low on emotional stability are unbalanced and more reactive to stress. We put forward the argument that emotionally unstable expatriates react poorly to stressors and will more likely regard ordinary situations as threatening. Consequently, for emotionally unstable expatriates, host country mentors can help reducing the ambiguity and uncertainty that the expatriates experience in a new environment by providing reliable information about cultural norms and values (Carraher et al., 2008). Thus, host country mentors act as a relief to certain stressors for emotionally unstable expatriates, which in turn have a higher psychological well-being than emotionally unstable expatriates without a mentor.

However, host country mentorship might not be beneficial in every situation. In fact, while the majority of expatriate literature (Bozionelos, 2009; Crocitto et al., 2005; Fee et al., 2011; Mezias and Scandura, 2005; Zhuang et al., 2013) focuses on the positive outcomes of mentorship, several authors provide evidence that having a mentor is not always beneficial. For instance, Carraher et al. (2008) point out that host country mentors might be incapable of understanding expatriates' job tension. Likewise, they show that host country mentors only have a small positive impact on expatriates' organizational identification due to unfitting mentor-protégé communication.

While those dysfunctional aspects of mentorship are scarce in the expatriate management literature, a lively discussion on dysfunctional or negative aspects of mentor-protégé relationships can be found in the general mentoring literature (Eby and Allen, 2002). Based on this discussion, we argue that emotionally stable expatriates may consider a host country mentor as an additional stressor. Since cross-cultural mentoring partnerships are, due to cultural differences, rather difficult to maintain and have been posited to take place less frequently and to be less beneficial for the 
mentee than inter-cultural mentor relationships, expatriates might consider the host country mentor as an additional burden (Fee et al., 2011; Feldman et al., 1999; Feldman and Thomas, 1992; Toh and DeNisi, 2005). Additionally, they may feel pressured to meet the expectations of the host country mentor, which results in a higher stress level and in turn a lower psychological well-being (compared to emotionally stable expatriates without a host country mentor). This assumption is supported by the fact that under these circumstances the main needs behind emotional stability, namely getting along and finding meaning, are difficult to satisfy. The psychological well-being of emotionally stable expatriates may thus be decreased by host country mentors, due to the additional stress, which makes it more difficult for expatriates to get along and find meaning.

Finally, the findings reveal that host country mentorship has a positive effect on the relationship between openness and psychological well-being. As we argued in Hypothesis 7a and illustrated in Error! Reference source not found., open-minded expatriates have a higher psychological well-being if they are supported by a host country mentor as compared to open-minded expatriates without a mentor. In other words, open-minded expatriates are able to cherish tips and advice of the host country mentor, even if this means replacing learned and frequently applied procedures, whereas less open-minded expatriates feel stressed when confronted with unfamiliar procedures.

-- Insert Figure 4 about here --

This finding is in line with the assumption that openness is motivated by finding meaning (Hogan and Holland, 2003). By acting as a broker for the cultural knowledge needed during the assignment, host country mentors can actively support expatriates in finding meaning, which enhances well-being and explains the effect.

\section{CONTRIBUTIONS, IMPLICATIONS, AND LIMITATIONS}

By testing the effects of personality traits on psychological well-being against a dataset of 334 expatriates and introducing the moderating role of mentorship, this study advances our understanding of the effects of expatriates' personality on psychological well-being as an important outcome variable of international assignments. Moreover, by including mentorship and distinguishing between home and host country mentoring, we show that depending on expatriates' personalities, home and host country mentors have different beneficial and adverse effects on psychological well-being. This deepens our understanding of which kind of mentor should be assigned to whom and how mentoring can be tailored to the individual expatriate's needs. In particular, this study provides evidence that mentorship can, when not matched efficiently, even negatively impact the effects of personality traits on psychological well-being. 


\section{Theoretical implications}

Our study contributes to the literature in several ways. First, even though personality traits are considered to be the most important antecedents of expatriate cross-cultural adjustment and psychological well-being (Shaffer et al., 2006), only a surprisingly limited number of studies in the expatriate management literature focused on the effects of personality traits on psychological well-being during international assignments (e.g. Huang et al., 2005; Van Oudenhoven et al., 2003; Peltokorpi and Froese, 2012, 2014, Selmer and Lauring, 2013, 2014; Shaffer et al., 2006). In particular, although several studies refer to possible antecedents of psychological well-being as outcome variables, the effects of personality traits on psychological well-being have never been explicitly studied. With our study we further add to the literature by enhancing the knowledge on the research gap concerning mentoring and its relation with personality traits and psychological well-being of expatriates, which we identified in the beginning.

Furthermore, we extended the scope of socioanalytic theory by introducing the concept of mentoring as an instrument to support expatriates with the fulfillment of their basic needs. We argued that challenges of international assignments can be interpreted as barriers to the satisfaction of the three basic human needs as postulated in socioanalytic theory (getting along, getting ahead, and finding meaning) and found that the different motives behind individuals' personality traits can help understand the context of expatriate personalities and psychological well-being. Based on socioanalytic theory, on the one hand, we further found that mentoring can - in certain cases - strengthen the positive influence of personality traits on psychological well-being. On the other hand, we found that mentoring may also have negative effects on the relationship between personality traits and psychological well-being. We contribute to socioanalytic theory by indicating that mentors can help to satisfy the needs but, depending on the personality of the expatriate, also be a barrier to satisfaction of the needs. This finding is an important enhancement of socioanalytic theory, as it clearly shows how instruments like mentoring can enable or challenge individuals' needs to get ahead, get along, and find meaning.

\section{Managerial implications}

Our study has several implications for the management of expatriates. First and foremost, based on a fairly large sample, the study recommends that companies should not only rely on work-related selection criteria such as technical skills (Toh and DeNisi, 2005), but should additionally consider personality traits as important criteria for the selection of expatriates. As personality traits explain about 20 percent of the variance in psychological well-being, we are very confident that considering personality traits during the selection decision will certainly help companies to reduce 
expatriate failure significantly. Even though psychological well-being does not guarantee that expatriates will be successful during their assignments, previous research has outlined that poor adjustment and a low psychological wellbeing is one of the major reason for expatriate failure (Bhaskar-Shrinivas et al., 2005). In fact, expatriate literature highlights that psychological well-being shows strong positive correlations with all three dimensions of expatriate adjustment (Nicholson and Imaizumi, 1993; Selmer, 1998). Moreover, given the limited resources of companies and the high costs of expatriation, our study provides basic concepts to companies as to how and for whom to allocate a mentor. A concrete recommendation could be that personality tests should be done with both expatriates and mentors, in order to categorize them and match the most efficient pairs. For instance, as the findings reveal that emotionally stable expatriates will achieve a higher psychological well-being without a host country mentor, it seems reasonable not to offer host country mentorship for those expatriates. Hence, our study discloses some cost-saving potential for MNCs to better allocate the limited possibilities of available host country mentors.

\section{Limitations}

This study is not without limitations, which should be kept in mind when interpreting the results and which offer fruitful avenues for future research. First, all measures are based on self-reports from the expatriates, which can artificially increase effect strengths (e.g., social desirability, consistency motive) (Podsakoff and Organ, 1986). As personality traits and psychological well-being are hard to grasp objectively by self-reported data, it might be reasonable

that future studies include additional sources, such as the assessment of on-site peers or family members. Second, we employed the Big Five Framework, which is one of the most commonly applied frameworks when investigating personality traits in expatriate literature (Caligiuri, 2000a, 2000b; Shaffer et al., 2006). However, recent studies pass criticism on the framework and recommend to apply narrower personality traits schemes such as the Multicultural Personality Questionnaire (MPQ) when analyzing behavior in work-related contexts (Peltokorpi and Froese, 2012). Therefore, future studies may replicate the study using the MPQ and compare the effects on psychosocial well-being. Another factor which needs to be considered is that individuals from different cultures may be characterized by different personality traits (Hofstede and McCrae, 2004). In a culture which is rather introverted, an expatriate who is very extraverted, may irritate people, which may have counterproductive effects (Shaffer et al., 2006). However, as there is not such a thing like a threshold concerning the acceptability of personality traits in different cultures, it is difficult to differentiate here. Future studies could, however, take into account the manifestation of personality traits within the cultures studied and its effects. 
Finally, even though this is the first study to connect personality traits with mentoring in the context of international assignments and therefore advances our understanding in this field, additional research should investigate further aspects of mentoring such as perceived support, cross-gender mentoring, senior vs. step-ahead vs. peer mentoring, and formal vs. informal mentoring. However, those aspects bring additional challenges when comparing expatriates with and without a mentor (censored, truncated data). Therefore, we can only recommend to think about a reasonable study design and analysis technique (Tobit regression, censored regression).

Despite these limitations, the present study makes a vital contribution to the expatriate management literature and aims at stimulating further research on personality traits and mentoring with regard to psychological well-being or other relevant outcome variables. 


\section{REFERENCES}

Abe, H. and Wiseman, R.L. (1983), "A cross-cultural confirmation of the dimensions of intercultural effectiveness", International Journal of Intercultural Relations, Vol. 7 No. 1, pp. 53-67.

Aiken, L.S. and West, S.G. (1991), Multiple Regression: Testing and Interpreting Interactions, Sage, Thousand Oaks, CA.

Alserhan, B.A., Forstenlechner, I. and Al-Nakeeb, A. (2009), "Employees' attitudes towards diversity in a nonwestern context", Employee Relations, Vol. 32 No. 1, pp. 42-55.

Al-Waqfi, M. and Forstenlechner, I. (2010), "Stereotyping of citizens in an expatriate-dominated labour market: Implications for workforce localisation policy", Employee Relations, Vol. 32 No. 4, pp. 364-381.

Ambrosius, J. (2016), "Strategic talent management in emerging markets and its impact on employee retention: Evidence from Brazilian MNCs", Thunderbird International Business Review, online first, DOI: 10.1002/tie.21799.

Armstrong, J.S. and Overton, T.S. (1977), "Estimating nonresponse bias in mail surveys", Journal of Marketing Research, Vol. 14 No. 3, pp. 396-402.

Aryee, S. and Stone, R.J. (1996), "Work experiences, work adjustment and psychological well-being of expatriate employees in Hong Kong”, The International Journal of Human Resource Management, Vol. 7 No. 1, pp. 150164.

Bader, B., Berg, N. and Holtbrügge, D. (2015), "Expatriate performance in terrorism-endangered countries: The role of family and organizational support", International Business Review, Vol. 24 No. 5, pp. 849-860.

Bader, B. and Schuster, T. (2015), "Expatriate social networks in terrorism-endangered countries: An empirical analysis in Afghanistan, India, Pakistan, and Saudi Arabia", Journal of International Management, Vol. 21 No. 1, pp. 63-77.

Bhaskar-Shrinivas, P., Harrison, D.A., Shaffer, M.A. and Luk, D.M. (2005), "Input-based and time-based models of international adjustment: Meta-analytic evidence and theoretical extensions", Academy of Management Journal, Vol. 48 No. 2, pp. 257-281.

Black, J.S. and Mendenhall, M.E. (1990), "Cross-cultural training effectiveness: A review and a theoretical framework for future research", Academy of Management Review, Vol. 15 No. 1, pp. 113-136.

Black, J.S. and Stephens, G.K. (1989), "The influence of the spouse on American expatriate adjustment and intent to stay in Pacific Rim overseas assignments", Journal of Management, Vol. 15 No. 4, pp. 529-544.

De Boer, A.G.E.M., Van Lanschot, J.J.B., Stalmeier, P.F.M., Van Sandick, J.W., Hulscher, J.B.F., De Haes, J.C.J.M. and Sprangers, M.A.G. (2004), "Is a single-item visual analogue scale as valid, reliable and responsive as multiitem scales in measuring quality of life?”, Quality of Life Research, Vol. 13 No. 2, pp. 311-320.

Bozionelos, N. (2009), "Expatriation outside the boundaries of the multinational corporation: a study with expatriate nurses in Saudi Arabia", Human Resource Management, Vol. 48 No. 1, pp. 111-134.

Brewster, C., Suutari, V. and Bonache, J. (2005), "Job satisfaction among expatriates, repatriates and domestic employees: The perceived impact of international assignments on work-related variables", Personnel Review, Vol. 34 No. 1, pp. 110-124.

Bright, M.I. (2005), “Can Japanese mentoring enhance understanding of Western mentoring?”, Employee Relations, Vol. 27 No. 4, pp. 325-339.

Caligiuri, P.M. (1997), “Assessing expatriate success: Beyond just 'being there”, in Aycan, Z. (Ed.), New Approaches to Employee Management, Elsevier Science/JAI Press, Greenwich, CT, pp. 117-140.

Caligiuri, P.M. (2000a), "The big five personality characteristics as predictors of expatriate's desire to terminate the assignment and supervisor-rated performance", Personnel Psychology, Vol. 53 No. 1, pp. 67-88. 
Caligiuri, P.M. (2000b), "Selecting expatriates for personality characteristics: A moderating effect of personality on the relationship between host national contact and cross-cultural adjustment", Management International Review, Vol. 40 No. 1, pp. 61-80.

Cao, L., Hirschi, A. and Deller, J. (2014), "Perceived organizational support and intention to stay in host countries among self-initiated expatriates: the role of career satisfaction and networks", The International Journal of Human Resource Management, Vol. 25 No. 14, pp. 2013-2032.

Carraher, S., Sullivan, S.E. and Crocitto, M.M. (2008), "Mentoring across global boundaries: An empirical examination of home-and host-country mentors on expatriate career outcomes", Journal of International Business Studies, Vol. 39 No. 8, pp. 1310-1326.

Chang, S.-J., Van Witteloostuijn, A. and Eden, L. (2010), "From the editors: Common method variance in international business research", Journal of International Business Studies, Vol. 41 No. 2, pp. 178-184.

Chao, G.T., Walz, P.M. and Gardner, P.D. (1992), "Formal and informal mentorships: A comparison on mentoring functions and contrast with nonmentored counterparts", Personnel Psychology, Vol. 45 No. 3, pp. 619-636.

Chen, G., Kirkman, B.L., Kim, K., Farh, C.I.C. and Tangirala, S. (2010), "When does cross-cultural motivation enhance expatriate effectiveness? A multilevel investigation of the moderating roles of subsidiary support and cultural distance", Academy of Management Journal, Vol. 53 No. 5, pp. 1110-1130.

Chiu, Y.-P., Wu, M., Zhuang, W.-L. and Hsu, Y.-Y. (2009), "Influences on expatriate social networks in China", The International Journal of Human Resource Management, Vol. 20 No. 4, pp. 790-809.

Crocitto, M.M., Sullivan, S.E. and Carraher, S.M. (2005), "Global mentoring as a means of career development and knowledge creation: A learning-based framework and agenda for future research", Career Development International, Vol. 10 No. 6/7, pp. 522-535.

Dawson, J.F. (2014), "Moderation in management research: What, why, when, and how", Journal of Business and Psychology, Vol. 29 No. 1, pp. 1-19.

Devonish, D. (2013), "Workplace bullying, employee performance and behaviors: The mediating role of psychological well-being", Employee Relations, Vol. 35 No. 6, pp. 630-647.

Doherty, N., Richardson, J., Thorn, K., Doherty, N., Richardson, J. and Thorn, K. (2013), "Self-initiated expatriation and self-initiated expatriates: Clarification of the research stream", Career Development International, Vol. 18 No. 1, pp. 97-112.

Downes, M., Thomas, A.S. and Singley, R.B. (2002), "Predicting expatriate job satisfaction: the role of firm internationalization", Career Development International, Vol. 7 No. 1, pp. 24-36.

Downes, M., Varner, I.I. and Hemmasi, M. (2010), "Individual profiles as predictors of expatriate effectiveness", Competitiveness Review: An International Business Journal, Vol. 20 No. 3, pp. 235-247.

Eby, L.T. and Allen, T.D. (2002), "Further investigation of protégés' negative mentoring experiences patterns and outcomes", Group \& Organization Management, Vol. 27 No. 4, pp. 456-479.

Fee, A., McGrath-Champ, S. and Yang, X. (2011), "Expatriate performance management and firm internationalization: Australian multinationals in China", Asia Pacific Journal of Human Resources, Vol. 49 No. 3, pp. 365-384.

Feldman, D.C. and Bolino, M.C. (1999), "The impact of on-site mentoring on expatriate socialization: A structural equation modelling approach", The International Journal of Human Resource Management, Vol. 10 No. 1, pp. $54-71$.

Feldman, D.C., Folks, W.R. and Turnley, W.H. (1999), "Mentor-protégé diversity and its impact on international internship experiences", Journal of Organizational Behavior, Vol. 20 No. 5, pp. 597-611.

Feldman, D.C. and Thomas, D.C. (1992), "Career management issues facing expatriates", Journal of International Business Studies, Vol. 23 No. 2, pp. 271-293.

Firth, B.M., Chen, G., Kirkman, B.L. and Kim, K. (2014), "Newcomers abroad: Expatriate adaptation during early 
phases of international assignments", Academy of Management Journal, Vol. 57 No. 1, pp. 280-300.

Florkowski, G. and Fogel, D. (1999), "Expatriate adjustment and commitment: The role of host-unit treatment", The International Journal of Human Resource Management, Vol. 10 No. 5, pp. 783-807.

Froese, F.J., Peltokorpi, V. and Ko, K.A. (2012), "The influence of intercultural communication on cross-cultural adjustment and work attitudes: Foreign workers in South Korea", International Journal of Intercultural Relations, Vol. 36 No. 3, pp. 331-342.

Gosling, S.D., Rentfrow, P.J. and Swann Jr., W.B. (2003), "A very brief measure of the Big-Five personality domains", Journal of Research in Personality, Vol. 37 No. 6, pp. 504-528.

Grant, C.A., Wallace, L.M. and Spurgeon, P.C. (2013), "An exploration of the psychological factors affecting remote e-worker's job effectiveness, well-being and work-life balance", Employee Relations, Vol. 35 No. 5, pp. 527546.

Guimond, S., Dif, S. and Aupy, A. (2002), "Social identity, relative group status and intergroup attitudes: When favourable outcomes change intergroup relations... for the worse", European Journal of Social Psychology, Vol. 32 No. 6, pp. 739-760.

Gupta, R., Banerjee, P. and Gaur, J. (2012), "Exploring the role of the spouse in expatriate failure: a grounded theorybased investigation of expatriate'spouse adjustment issues from India", The International Journal of Human Resource Management, Vol. 23 No. 17, pp. 3559-3577.

Haggard, D.L., Dougherty, T.W., Turban, D.B. and Wilbanks, J.E. (2011), "Who is a mentor? A review of evolving definitions and implications for research", Journal of Management, Vol. 37 No. 1, pp. 280-304.

Hair, J.F., Black, W.C., Babin, B.J., Anderson, R.E. and Tatham, R.L. (2006), Multivariate Data Analysis, 6th ed., Pearson, Upper Saddle River.

Harman, H.H. (1976), Modern Factor Analysis, University of Chicago Press, Chicago.

Harzing, A.-W. (1995), "The persistent myth of high expatriate failure rates", The International Journal of Human Resource Management, Vol. 6 No. 2, pp. 457-474.

Harzing, A.-W. (2001), "An analysis of the functions of international transfer of managers in MNCs", Employee Relations, Vol. 23 No. 6, pp. 581-598.

Harzing, A.-W. and Christensen, C. (2004), "Expatriate failure: Time to abandon the concept?", Career Development International, Vol. 9 No. 7, pp. 616-626.

Heimann, B. and Pittenger, K.K.S. (1996), "The impact of formal mentorship on socialization and commitment of newcomers", Journal of Managerial Issues, Vol. 8 No. 1, pp. 108-117.

Hemmasi, M., Downes, M. and Varner, I.I. (2010), “An empirically-derived multidimensional measure of expatriate success: reconciling the discord", The International Journal of Human Resource Management, Vol. 21 No. 7, pp. 982-998.

Hoersting, R.C. and Jenkins, S.R. (2011), "No place to call home: Cultural homelessness, self-esteem and crosscultural identities", International Journal of Intercultural Relations, Vol. 35 No. 1, pp. 17-30.

Hofstede, G. and McCrae, R.R. (2004), "Personality and culture revisited: Linking traits and dimensions of culture", Cross-Cultural Research, Vol. 38 No. 1, pp. 52-88.

Hogan, J.C. and Holland, B. (2003), "Using theory to evaluate personality and job-performance relations: a socioanalytic perspective", Journal of Applied Psychology, Vol. 88 No. 1, pp. 100 -112.

Hogan, R.J. and Blickle, G. (2013), "Socioanalytic theory", Handbook of Personality at Work, Routledge, New York, NY, pp. 53-70.

Hogan, R.J., Jones, W.H. and Cheek, J.M. (1985), "Socioanalytic theory: An alternative to armadillo psychology", in Schlenker, B.R. (Ed.), The Self and Social Life, McGraw Hill, New York, pp. 175-198.

Hogan, R.J. and Roberts, B.W. (2000), “A Socioanalytic Perspective on Person-Environment”, Person-Environment 
Psychology: New Directions and Perspectives, Psychology Press.

Hogan, R.J. and Shelton, D. (1998), “A socioanalytic perspective on job performance”, Human Performance, Vol. 11 No. 2-3, pp. 129-144.

Holtbrügge, D. and Ambrosius, J. (2015), “Mentoring, skill development, and career success of foreign expatriates", Human Resource Development International, Vol. 18 No. 3, pp. 278-294.

Huang, T.-J., Chi, S.-C. and Lawler, J.J. (2005), "The relationship between expatriates' personality traits and their adjustment to international assignments", The International Journal of Human Resource Management, Vol. 16 No. 9, pp. 1656-1670.

Huff, K.C. (2013), "Language, cultural intelligence and expatriate success", Management Research Review, Vol. 36 No. 6, pp. 596-612.

Huff, K.C., Song, P. and Gresch, E.B. (2014), "Cultural intelligence, personality, and cross-cultural adjustment: A study of expatriates in Japan", International Journal of Intercultural Relations, Vol. 38, pp. 151-157.

Johnson, E.C., Kristof-Brown, A.L. and Klein, M.R. (2003), "Expatriate social ties: Personality antecedents and consequences for adjustment", International Journal of Selection and Assessment, Vol. 11 No. 4, pp. 277-288.

Kim, K. and Slocum, J.W. (2008), "Individual differences and expatriate assignment effectiveness: The case of USbased Korean expatriates", Journal of World Business, Vol. 43 No. 1, pp. 109-126.

Kraimer, M.L., Wayne, S.J. and Jaworski, R.A. (2001), "Sources of support and expatriate performance: The mediating role of expatriate adjustment", Personnel Psychology, Vol. 54 No. 1, pp. 71-100.

Lazarova, M., Westman, M. and Shaffer, M.A. (2010), "Elucidating the positive side of the work-family interface on international assignments: A model of expatriate work and family performance", Academy of Management Review, Vol. 35 No. 1, pp. 93-117.

Lee, L.-Y., Veasna, S. and Wu, W.-Y. (2013), "The effects of social support and transformational leadership on expatriate adjustment and performance: The moderating roles of socialization experience and cultural intelligence", Career Development International, Vol. 18 No. 4, pp. 377-415.

Li, L.J. and Rothstein, M. (2009), “The Role of Social Networks on Expatriate Effectiveness", International Journal of Business Research, Vol. 9 No. 2, pp. 94-108.

Lounsbury, J.W., Loveland, J.M., Sundstrom, E.D., Gibson, L.W., Drost, A.W. and Hamrick, F.L. (2003), “An investigation of personality traits in relation to career satisfaction", Journal of Career Assessment, Vol. 11 No. 3, pp. 287-307.

McClelland, R. (2009), “The Dark Side of Mentoring Explaining Mentor-on-Mentee Aggression”, International Journal of Applied Philosophy, Vol. 23 No. 1, pp. 61-86.

McNulty, Y. and De Cieri, H. (2016), "Linking global mobility and global talent management: the role of ROI", Employee Relations, Vol. 38 No. 1, pp. 8-30.

Mendenhall, M.E. and Oddou, G.R. (1985), "The dimensions of expatriate acculturation: A review", Academy of Management Review, Vol. 10 No. 1, pp. 39-47.

Mezias, J.M. and Scandura, T.A. (2005), “A needs-driven approach to expatriate adjustment and career development: A multiple mentoring perspective", Journal of International Business Studies, Vol. 36 No. 5, pp. 519-538.

Minbaeva, D.B. and Michailova, S. (2004), "Knowledge transfer and expatriation in multinational corporations: The role of disseminative capacity", Employee Relations, Vol. 26 No. 6, pp. 663-679.

Morris, M.A. and Robie, C. (2001), "A meta-analysis of the effects of cross-cultural training on expatriate performance and adjustment", International Journal of Training and Development, Vol. 5 No. 2, pp. 112-125.

Morrison, E.W. (1993), "Longitudinal study of the effects of information seeking on newcomer socialization.", Journal of Applied Psychology, Vol. 78 No. 2, p. 173.

Motowildo, S.J., Borman, W.C. and Schmit, M.J. (1997), “A theory of individual differences in task and contextual 
performance", Human Performance, Vol. 10 No. 2, pp. 71-83.

Mullen, E.J. (1994), "Framing the mentoring relationship as an information exchange", Human Resource Management Review, Vol. 4 No. 3, pp. 257-281.

Nagy, M.S. (2002), "Using a single item approach to measure facet job satisfaction", Journal of Occupational and Organizational Psychology, Vol. 75 No. 1, pp. 77-86.

Nicholson, N. and Imaizumi, A. (1993), "The adjustment of Japanese expatriates to living and working in Britain", British Journal of Management, Vol. 4 No. 2, pp. 119-134.

Nunally, J.C. and Bernstein, I.H. (1978), Psychometric Theory, 2nd ed., McGraw-Hill, New York.

Nurmi, N. and Hinds, P.J. (2016), "Job complexity and learning opportunities: A silver lining in the design of global virtual work”, Journal of International Business Studies, Vol. 47 No. 6, pp. 631-654.

O’Sullivan, S.L. (1999), "The distinction between stable and dynamic cross-cultural competencies: Implications for expatriate trainability", Journal of International Business Studies, Vol. 30 No. 4, pp. 709-725.

Ones, D.S. and Viswesvaran, C. (1997), "Personality determinants in the prediction of aspects of expatriate job success.”, in Aycan, Z. (Ed.), Expatriate Management: Theory and Practice, Elsevier Science/JAI Press, Greenwich, CT.

Ones, D.S. and Viswesvaran, C. (1999), "Relative importance of personality dimensions for expatriate selection: A policy capturing study", Human Performance, Vol. 12 No. 3-4, pp. 275-294.

Van Oudenhoven, J.P., Mol, S. and Van der Zee, K.I. (2003), "A study of the adjustment of Western expatriates in Taiwan ROC with the Multicultural Personality Questionnaire (MPQ)", Asian Journal of Social Psychology, Vol. 6 No. 2, pp. 159-170.

Pate, J. and Scullion, H. (2010), “The changing nature of the traditional expatriate psychological contract", Employee Relations, Vol. 32 No. 1, pp. 56-73.

Pawar, B.S. (2016), "Workplace spirituality and employee well-being: an empirical examination", Employee Relations, Vol. 38 No. 6, online first.

Peltokorpi, V. (2010), "Intercultural communication in foreign subsidiaries: The influence of expatriates' language and cultural competencies", Scandinavian Journal of Management, Vol. 26 No. 2, pp. 176-188.

Peltokorpi, V. and Froese, F.J. (2012), "The impact of expatriate personality traits on cross-cultural adjustment: A study with expatriates in Japan”, International Business Review, Vol. 21 No. 4, pp. 734-746.

Peltokorpi, V. and Froese, F.J. (2014), "Expatriate personality and cultural fit: The moderating role of host country context on job satisfaction", International Business Review, Vol. 23 No. 1, pp. 293-302.

Podsakoff, P.M., MacKenzie, S.B., Lee, J.-Y. and Podsakoff, N.P. (2003), "Common method biases in behavioral research: A critical review of the literature and recommended remedies", Journal of Applied Psychology, Vol. 88 No. 5, pp. 879-903.

Podsakoff, P.M. and Organ, D.W. (1986), "Self-Reports in organizational research: Problems and prospects", Journal of Management, Vol. 12 No. 4, pp. 531-544.

Rajasekar, J. and Renand, F. (2013), "Culture shock in a global world: factors affecting culture shock experienced by expatriates in Oman and Omani expatriates abroad", International Journal of Business and Management, Vol. 8 No. 13 , p. 144-160.

Reiche, B.S., Kraimer, M.L. and Harzing, A.-W. (2011), "Why do international assignees stay? An organizational embeddedness perspective", Journal of International Business Studies, Vol. 42 No. 4, pp. 521-544.

Robins, R.W. (2001), "Measuring global self-esteem: Construct validation of a single-item measure and the Rosenberg Self-Esteem Scale", Personality and Social Psychology Bulletin, Vol. 27 No. 2, pp. 151-161.

Ryff, C.D. and Keyes, C.L.M. (1995), "The structure of psychological well-being revisited”, Journal of Personality and Social Psychology, Vol. 69 No. 4, pp. 719-727. 
Saucier, G. (1994), "Mini-markers: A brief version of Goldberg's unipolar Big-Five markers", Journal of Personality Assessment, Vol. 63 No. 3, pp. 506-516.

Selmer, J. (1998), "Expatriation: Corporate policy, personal intentions and international adjustment", The International Journal of Human Resource Management, Vol. 9 No. 6, pp. 996-1007.

Selmer, J. (2001), "Expatriate selection: Back to basics?", The International Journal of Human Resource Management, Vol. 12 No. 8, pp. 1219-1233.

Selmer, J. and Lauring, J. (2013), "Dispositional affectivity and work outcomes of expatriates", International Business Review, Elsevier Ltd, Vol. 22 No. 3, pp. 568-577.

Selmer, J. and Lauring, J. (2014), "Mobility and emotions: dispositional affectivity and adjustment of self-initiated expatriates", International Studies of Management \& Organization, Vol. 44 No. 3, pp. 25-43.

Shaffer, M.A., Harrison, D.A., Gregersen, H.B., Black, J.S. and Ferzandi, L. (2006), "You can take it with you: Individual differences and expatriate effectiveness", Journal of Applied Psychology, Vol. 91 No. 1, pp. 109125 .

Shay, J.P. and Baack, S. (2006), "An empirical investigation of the relationships between modes and degree of expatriate adjustment and multiple measures of performance", International Journal of Cross Cultural Management, Vol. 6 No. 3, pp. 275-294.

Simeon, R. and Fujiu, K. (2000), "Cross-cultural adjustment strategies of Japanese spouses in Silicon Valley", Employee Relations, Vol. 22 No. 6, pp. 594-611.

Stroh, L.K. (2016), "Predicting turnover among repatriates: can organizations affect retention rates? Predicting turnover among repatriates: can organizations affect retention rates ?", Vol. 6 No. 2, pp. 443-456.

Swaak, R.A. (1995), "Expatriate failures too many, too much cost, too little planning", Compensation \& Benefits Review, Vol. 27 No. 6, pp. 47-55.

Toh, S.M. and DeNisi, A.S. (2005), "A local perspective to expatriate success", The Academy of Management Executive, Vol. 19 No. 1, pp. 132-146.

Tung, R.L. (1987), "Expatriate assignments: Enhancing success and minimizing failure", The Academy of Management Executive, Vol. 1 No. 2, pp. 117-125.

Turban, D.B. and Lee, F.K. (2007), "The Role of Personality in Mentoring Relationships", in Ragins, B.R. and Kram, K.E. (Eds.), The Handbook of Mentoring at Work: Theory, Research, and Practice, Sage Publications, pp. 2150.

Wang, D., Feng, T., Freeman, S., Fan, D. and Zhu, C.J. (2014), "Unpacking the 'skill-cross-cultural competence' mechanisms: Empirical evidence from Chinese expatriate managers", International Business Review, Vol. 23 No. 3, pp. 530-541.

Wang, D., Freeman, S. and Zhu, C.J. (2013), "Personality traits and cross-cultural competence of Chinese expatriate managers: A socio-analytic and institutional perspective", The International Journal of Human Resource Management, Vol. 24 No. 20, pp. 3812-3830.

Wang, X. and Kanungo, R.N. (2004), "Nationality, social network and psychological well-being: Expatriates in China", The International Journal of Human Resource Management, Vol. 15 No. 4-5, pp. 775-793.

Wang, X. and Nayir, D.Z. (2006), "How and when is social networking important? Comparing European expatriate adjustment in China and Turkey", Journal of International Management, Vol. 12 No. 4, pp. 449-472.

Wanous, J.P., Poland, T.D., Premack, S.L. and Davis, K.S. (1992), "The effects of met expectations on newcomer attitudes and behaviors: a review and meta-analysis.", Journal of Applied Psychology, Vol. 77 No. 3, pp. 288297.

Wright, T.A. and Cropanzano, R. (2000), "Psychological well-being and job satisfaction as predictors of job performance", Journal of Occupational Health Psychology, Vol. 5 No. 1, pp. 84-94. 
Yeaton, K. and Hall, N. (2008), "Expatriates: Reducing failure rates", Journal of Corporate Accounting \& Finance, Vol. 19 No. 3, pp. 75-78.

Young, A.M. and Perrewe, P.L. (2000), "What did you expect? An examination of career-related support and social support among mentors and protégés", Journal of Management, Vol. 26 No. 4, pp. 611-632.

Zhuang, W.-L., Wu, M. and Wen, S.-L. (2013), "Relationship of mentoring functions to expatriate adjustments: comparing home country mentorship and host country mentorship", The International Journal of Human Resource Management, Vol. 24 No. 1, pp. 35-49. 